\title{
Use of momentum flux of tsunami overland flow as an indicator of potential damage to buildings
}

\author{
Janaka J. Wijetunge \\ Department of Civil Engineering, Faculty of Engineering, University of Peradeniya, Peradeniya.
}

Submitted: 16 March 2009; Accepted: 18 December 2009

\begin{abstract}
The mega-tsunami of December 2004 caused massive loss of life and damage to property in Sri Lanka and in many other countries bordering the Indian Ocean. Although the destruction caused was unprecedented, given the seemingly low probability of occurrence of destructive tsunami events affecting Sri Lanka, all structures in the vulnerable areas of the coastal belt are not expected to be designed or retrofitted to withstand a future tsunami. However, if it is necessary to locate critical infrastructure in the inundation zone, such structures ought to be designed for tsunami impact to ensure their proper functioning in the event of a disaster. The design of load bearing members of such critical structures requires prior information about the expected intensity of tsunami impact and loading. Although most tsunami hazard maps typically present spatial variations of the flow depth and the flow velocity, it is likely that the combined effect of these two parameters is more reflective of the potential damage to structures. Accordingly, this paper examines the effectiveness of momentum flux, which is proportional to the product of water depth and square of velocity, as an indicator of the potential tsunami loading on structures. A numerical model based on non-linear shallow water equations was used to compute the spatial variations of the flow depth, the velocity and the momentum flux as a case study for four cities in Sri Lanka, which were heavily affected by the 2004 tsunami. The computed values of the above three flow parameters are compared with field data relating to the spatial distribution of the number of houses and other buildings damaged due to the 2004 tsunami. The field observations of the spatial distribution of the percentage of houses and buildings damaged correlate better with the momentum flux than with the flow depth or the flow velocity.
\end{abstract}

Keywords: Critical structures, flow velocity, inundation, momentum flux, tsunami, water depth.

\section{INTRODUCTION}

The mega-thrust earthquake of moment magnitude 9.3 that occurred on December 26, 2004 in the AndamanSunda trench caused massive loss of life and damage to property in the coastal belts of 12 countries bordering the Indian Ocean. In Sri Lanka, 13 of the 14 districts lying along the coastal belt were affected: the death toll was over 35,000 with 20,000 injured and about 100,000 dwellings and other buildings either completely or partially damaged, leaving half a million people homeless and causing massive disruption to livelihoods ${ }^{1}$. The damage and losses to the vital sectors of the economy and to the infrastructure, the services and the environment were estimated to be over Rs. 200 billion $^{2}$ which was nearly $10 \%$ of the country's Gross Domestic Product (GDP) at the time.

The enormity of this unprecedented tragedy clearly showed the potential vulnerability of the coastal belt of Sri Lanka to the forces of nature, especially to the extreme geological and meteorological happenings in the vast expanse of the Indian Ocean around the country. However, the manner in which we ought to respond to the threat of any hazard must be based primarily on its severity and recurrence interval. Accordingly, our approach and strategy in mitigating the risk from a future tsunami should be formulated based on a probabilistic assessment of the severity and the frequency of the tsunami threat to Sri Lanka. For example, if a December 2004 type tsunami was to occur, on an average, once in 50 to 100 years, one may argue that all structures built in the inundation zone should be made tsunami-resistant. However, if the December 2004 type tsunami is a once in 250 to 500 or more year event, questions may be 
raised about the applicability of such tsunami-resistant construction standards, since the life expectancy of a structure may be only 70 to 100 years. Several preliminary investigations based on plate tectonic theory as well as the history of past events in the Andaman-Sunda subduction zone seem to suggest that the frequency of recurrence of an ocean-wide tsunami similar to that which occurred in 2004 is very low ${ }^{3}$.

Therefore, given the seemingly low probability of occurrence of destructive tsunami events affecting Sri Lanka, not all buildings and other infrastructure in the vulnerable areas of the coastal belt are expected to be designed or retrofitted to withstand tsunami loading. However, if it is necessary to locate critical infrastructure such as hospitals, sewage treatment facilities, fire stations, power substations, harbour docks, bridges and communication systems in the inundation zone, such structures ought to be designed to withstand tsunami impact to ensure their proper functioning in the event of a disaster. Structures can be classified critical if the occupants are not sufficiently mobile to avoid injury or death during tsunami overland flow, or the facility is needed for disaster response activities or for maintenance and restoration of essential services in the inundation zone.

The design of load bearing members of such critical structures and vital infrastructure requires prior information about the expected intensity of tsunami impact and loading. Moreover, availability of information about the spatial distribution of the probable tsunami impact in the inundation zone will also enable coastal planners to avoid high risk areas and locate new development in less vulnerable areas.

A question then arises as to which flow parameter is more effective in describing and quantifying the potential impact of tsunami overland flow on structures. Although most tsunami hazard maps typically present the spatial distributions of the maximum values of water depth and flow velocities in the inundation zone $\mathrm{z}^{4-7}$, it may be argued that it is the combined effect of these two flow parameters that accurately reflect the intensity of tsunami loading which causes damage to structures, and not the water depth or the flow velocity alone. However, one flow parameter that reflects the effects of both the water depth and the flow velocity is the momentum flux which is proportional to the product of the water depth and the square of velocity. Accordingly, the primary objective of the present paper is to examine the effectiveness of momentum flux as an indicator of the potential tsunami loading on structures.
In the present study, a numerical code based on nonlinear shallow water equations was used to compute the spatial distributions of the instantaneous water depth, the flow velocity as well as the momentum flux of the onshore flooding caused by the 2004 tsunami as a case study for four cities on the south and east coasts of Sri Lanka, namely, Matara, Galle, Hambantota and Trincomalee (Figure 1). The calculated values of the above parameters across the computational domains in each of the four cities are compared with the data relating to the proportion of houses and other buildings damaged in each Grama Niladhari (GN) division ${ }^{1}$ due to the December 2004 tsunami. The analysis suggests that the mean values of the computed momentum flux correlates better with the percentage of housing and other buildings damaged in each GN division than with the water depth or the flow velocity taken alone.

\section{METHODS AND MATERIALS}

Definitions: The tsunami waves gain in height as they cross continental slopes into shallow water, and eventually, either break before arriving at the shoreline or merely surge over the nearshore bathymetry without breaking, depending on the wave characteristics and the slope of the nearshore sea bottom. A breaking tsunami wave front moves inland as a surging bore, whilst a non-breaking wave will appear as a fast rising tide with a rapid increase of water level causing flooding onshore. This turbulent, fast-moving flow results in damage, collapse, or floating away of buildings and vegetation as well as drowning of people.

Inundation distance is the maximum horizontal penetration of tsunami flooding in the direction normal to the shoreline, whilst run-up is the difference between the elevation of maximum tsunami penetration and

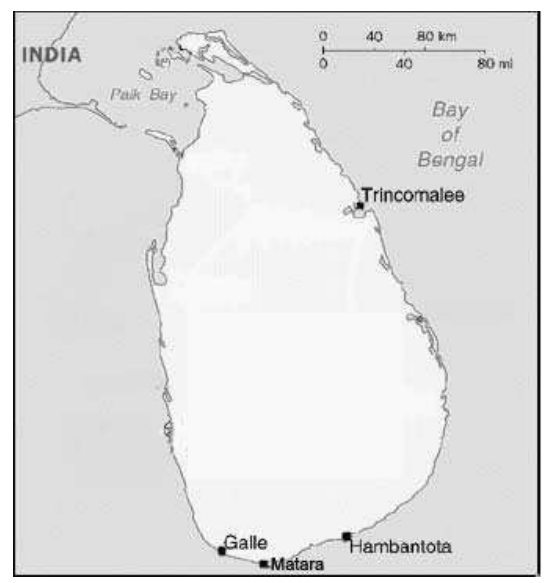

Figure 1: Locations of cities selected for the study 
the sea level at the time of the tsunami (Figure 2). The inundation distance and the run-up height of the overland flow depend on the wave characteristics, the nearshore bathymetry and the onshore topography, as well as the nature of any coastal structures and the type of land use. The water that ran up inland will run down (drain away) to the sea under gravity causing further damage and carrying off loose objects and people in its path as it retreats.

The following parameters pertaining to both the run-up and the run-down processes are usually employed to describe the tsunami impact onshore:

Maximum flow depth,

$h_{\text {max }}(x, y)=\left\lceil\eta(x, y, t)+h_{s}(x, y, t)\right\rceil_{\max }$

Maximum depth-averaged current speed,

$V_{\text {max }}(x, y)=\left|\left\{u^{2}(x, y, t)+v^{2}(x, y, t)\right\}^{1 / 2}\right|_{\text {max }}$

where, $h_{s}$ is the still water depth; $\square$ is the amplitude; $t$ is the time; $x$ and $y$, respectively, are the directions pointing to the east and the north; and $u$ and $v$, respectively, are the depth-averaged velocities in the $x$ and $y$ directions.

Regions with large flow depths in tsunami overland flow do not necessarily correlate with regions of large velocities $^{8}$. As a tsunami propagates over dry land, the flow depth decreases towards the point of maximum run-up where the velocity at the tip of the surging front becomes zero, indicating that in this case both $h$ and $V$ are small; however, during run-down under gravity, the flow depth could be comparatively smaller, but the velocity can be substantial depending on the ground slope. It may be argued that, rather than the water depth and the flow speeds taken separately, it is the combined effect of these two parameters that causes damage to structures. Accordingly, the maximum momentum flux of the overland flow defined as follows may be more useful in describing the potential tsunami impact onshore:

Maximum momentum flux per unit width normal to the flow,

$M_{\max }(x, y)=\left|\rho h(x, y, t) V^{2}(x, y, t)\right|_{\max }$

where, $\square$ is the density of sea water.

A Momentum Flux Index (MFI) is defined as follows:

$\mathrm{MFI}=\log _{10}\left(M_{\max }\right)$
A numerical model based on non-linear shallow water equations was used to compute the flow depths $(h)$ and flow velocities $(u, v)$ as well as the MFI across the areas of interest in the four cities.

Numerical model: The fault plane model and the hydrodynamic model used to simulate the generation and the propagation of the 2004 tsunami from its origin in the Andaman-Sunda trench to the shores of Sri Lanka is described below. The nested grid set-up used in the hydrodynamic model is also described.

Fault plane model: Seismic inversion models ${ }^{9}$ suggest that the rupture propagated approximately northward from the epicentre located at $\left(95.51^{\circ} \mathrm{E}, 3.25^{\circ} \mathrm{N}\right)$ along $1,200-1,300 \mathrm{~km}$ of the Andaman-Sunda fault line for about $8-10$ min causing up to $6 \mathrm{~m}$ of bottom subsidence and $10 \mathrm{~m}$ of uplift over a region $100-150 \mathrm{~km}$ wide across the subduction area.

A previous study ${ }^{10}$ employed available seismic data as well as hydrodynamic data to iteratively develop a 5-segment co-seismic tsunami source for the above 26 December 2004 event. In a subsequent study ${ }^{11}$, the numerical simulations based on this fault plane model showed good agreement with measured run-up heights along the Andaman coast of Thailand.

The contours of initial surface elevation for the above co-seismic tsunami source computed using Okada's dislocation model ${ }^{12}$ and reported in Grilli et al. ${ }^{10}$ is shown in Figure 3. Further, it is assumed here that the sea surface follows the sea bed deformation instantaneously. Note that in Figure 3, the continuous lines represent uplift and dashed lines represent subsidence, both at $1 \mathrm{~m}$ contour intervals in the range $-5 \mathrm{~m}$ to $+8 \mathrm{~m}$. The background bathymetry is also plotted in grey at $500 \mathrm{~m}$ contour intervals.

The present simulations employed the initial surface elevation from the above source mode $^{10}$.

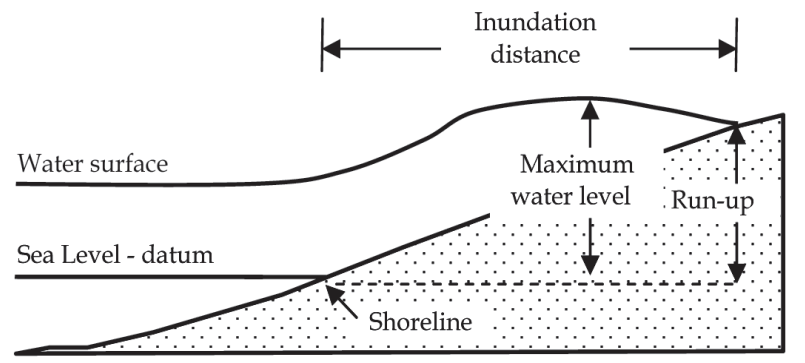

Figure 2: Definition sketch: tsunami run-up and inundation distance 
Grid set-up for hydrodynamic model: A dynamically coupled system of nested grids was employed to simulate the tsunami propagation from Andaman-Sunda subduction zone towards Sri Lanka and the subsequent inundation of the onshore terrain of the cities under study. The numerical simulations for the southern and the eastern coasts were carried out separately: the details of the nested grids employed to simulate tsunami inundation in Galle, Matara and Hambantota on the south coast and Trincomalee on the east coast are given in Table 1 and Table 2, respectively. The bathymetry data for the largest grid employed in the simulations, i.e., Grid 1, was obtained by interpolating ETOPO2 data $^{13}$ with a resolution of 2 arc minutes to a grid of 0.6765 arc minutes $(\sim 1250 \mathrm{~m})$ spacing.

The bathymetry data for Grids S2 (Table 1) and E2 (Table 2) with a grid resolution of 0.1353 arc minutes $(\sim 250 \mathrm{~m})$ as well as for Grids S3 and E3 (grid spacing $50 \mathrm{~m}$ ) were at first interpolated from ETOPO2 data and were then updated with data from the available navigation charts of the UK Hydrographic Office. These navigation charts typically covered depths down to about $3000-4000 \mathrm{~m}$ at scales of $1: 150,000$ or $1: 300,000$. The nearshore bathymetry of some areas was updated with higher resolution navigation charts at scales of 1:10,000 and $1: 15,000$.

Three fourth level grids with a grid spacing of $10 \mathrm{~m}$ were used to cover the three cities on the south coast: grids S41, S42 and S43 for Galle, Matara and Hambantota, respectively. The topographic data for these grids were obtained from high resolution LIDAR (Light Detection and Ranging) survey data (The precise digital earth model of the coastal areas of Sri Lanka, Project Director: Prof. Fabrizio Ferrucci, Italy) made available

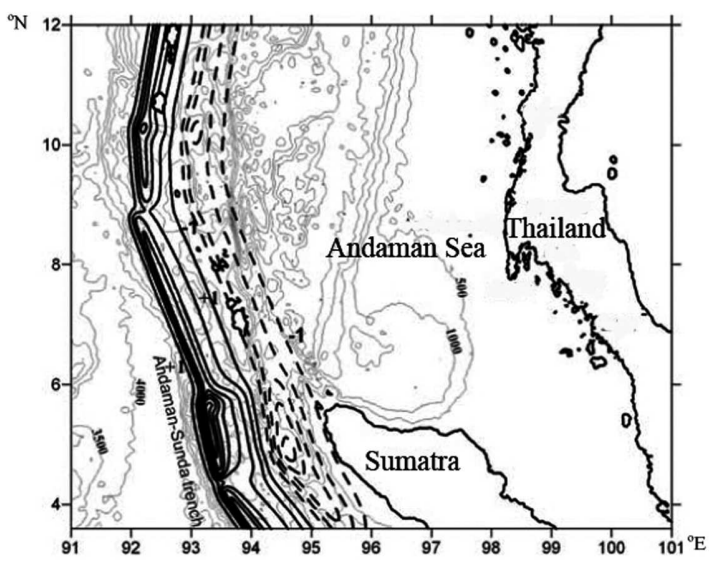

Figure 3: Initial surface elevation for tsunami source. Continuous lines represent uplift and dashed lines represent subsidence, both at $1 \mathrm{~m}$ contour intervals in the range $-5 \mathrm{~m}$ to $+8 \mathrm{~m}$ (after Ioualalen et al. $\left.{ }^{11}\right)$. to the author by the Ministry of Disaster Management and Human Rights of the Government of Sri Lanka. These LIDAR data have been acquired at a horizontal resolution of $1 \mathrm{~m}$ and a vertical resolution of not more than $0.3 \mathrm{~m}$ and were originally projected on to the UTM WGS84 - Zone 44N coordinate system. Subsequently, these LIDAR maps were projected on to the Geographic Coordinate System with WGS84 as the datum, and were subjected to ground truthing for validation.

The fourth level grid employed to simulate the inundation in the city of Trincomalee on the east coast (Grid E41 in Table 2) was constructed by utilizing 1:5000 scale digital topographic data obtained from the Survey Department of Sri Lanka as LIDAR data were not available for the east coast.

Hydrodynamic model formulation: The mathematical model used in the present work is the Cornell Multigrid Coupled Tsunami Model (COMCOT, coded in FORTRAN 90) which solves the non-linear shallow water equations on a dynamically coupled system of nested grids using a modified leap-frog finite difference numerical scheme. This model has been validated by experimental data ${ }^{14}$ and has been successfully used to investigate several historical tsunami events, including the 2004 Indian Ocean tsunami ${ }^{15-17}$.

Using a nested grid system, COMCOT is capable of simultaneously calculating the tsunami propagation in the ocean and the inundation in the targeted coastal zones. In the nested grid system, the inner (finer) grids adopt a smaller grid size and time step and are nested inside an outer (larger) grid. At the beginning of each time step, along the interface of two different grids, the volume flux, which is a product of water depth and depth-averaged velocity, is interpolated from the outer grids into inner grids. The water surface elevations and the volume fluxes in the inner grids are calculated and the resulting free surface elevations are averaged to update those values in the larger grids, which overlap the inner grid. The volume fluxes in the outer grid can also be updated. With this algorithm, we can capture nearshore features of tsunami dynamics with a high spatial and temporal resolution whilst maintaining a high computational efficiency ${ }^{16}$. To simulate onshore flooding, a moving boundary scheme described in $\mathrm{Cho}^{18}$ was used, in which the "shoreline" is defined as the interface between a wet grid and its adjacent dry grids. Along the "shoreline", the volume flux is assigned to be zero. Once the water surface elevation at the wet grid is higher than the land elevation in its adjacent dry grids, the "shoreline" is moved one grid toward the dry grid and the volume flux is no longer zero and needs to be calculated by the governing equations. 
Table 1: Model parameters for the nested grids - south coast

\begin{tabular}{|c|c|c|c|c|}
\hline \multirow{2}{*}{ Grid No. } & \multicolumn{2}{|c|}{$\begin{array}{c}\text { Extent of grid } \\
\text { (Geographic, WGS84) }\end{array}$} & \multirow{2}{*}{$\begin{array}{l}\text { No. of } \\
\text { grids }\end{array}$} & \multirow{2}{*}{$\begin{array}{c}\text { Grid } \\
\text { spacing }\end{array}$} \\
\hline & Eastward $\left({ }^{0} \mathrm{E}\right)$ & Northward $\left({ }^{0} \mathrm{~N}\right)$ & & \\
\hline 1 & $78.4000-98.2950$ & $0.0000-14.8987$ & $1765 \times 1320$ & $0.6765 \mathrm{~min}$ \\
\hline S2 & $79.2301-82.4061$ & $5.0143-6.4896$ & $1385 \times 640$ & $0.1353 \mathrm{~min}$ \\
\hline $\mathrm{S} 3$ & $80.1179-81.1954$ & $5.7804-6.1790$ & $2355 \times 870$ & $50 \mathrm{~m}$ \\
\hline S41 & $80.1883-80.2419$ & $5.9980-6.0511$ & $595 \times 590$ & $10 \mathrm{~m}$ \\
\hline S42 & $80.5176-80.5676$ & $5.8967-5.9611$ & $555 \times 715$ & $10 \mathrm{~m}$ \\
\hline S43 & $81.1031-81.1503$ & $6.0890-6.1589$ & $525 \times 775$ & $10 \mathrm{~m}$ \\
\hline
\end{tabular}

Table 2: Model parameters for the nested grids - east coast

\begin{tabular}{|c|c|c|c|c|}
\hline \multirow{2}{*}{ Grid No. } & \multicolumn{2}{|c|}{$\begin{array}{c}\text { Extent of grid } \\
(\text { Geographic, WGS84) }\end{array}$} & \multirow{2}{*}{$\begin{array}{l}\text { No. of } \\
\text { grids }\end{array}$} & \multirow{2}{*}{$\begin{array}{c}\text { Grid } \\
\text { spacing }\end{array}$} \\
\hline & Eastward $\left({ }^{\circ} \mathrm{E}\right)$ & Northward $\left({ }^{\circ} \mathrm{N}\right)$ & & \\
\hline 1 & $78.4000-98.2950$ & $0.0000-14.8987$ & $1765 \times 1320$ & $0.6765 \mathrm{~min}$. \\
\hline E2 & $80.9549-82.3620$ & $6.4673-8.9456$ & $625 \times 1100$ & $0.1353 \mathrm{~min}$. \\
\hline E3 & $81.1096-81.9889$ & $7.6187-8.6934$ & $1935 \times 2380$ & $50 \mathrm{~m}$ \\
\hline E41 & $81.2137-81.2538$ & $8.5656-8.5984$ & $445 \times 365$ & $10 \mathrm{~m}$ \\
\hline
\end{tabular}

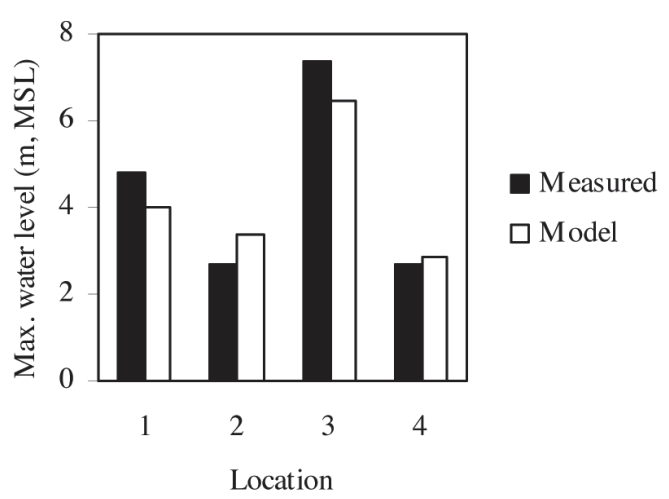

Figure 4: Comparison of computed maximum water levels with field measurements. See Table 3 for coordinates of locations

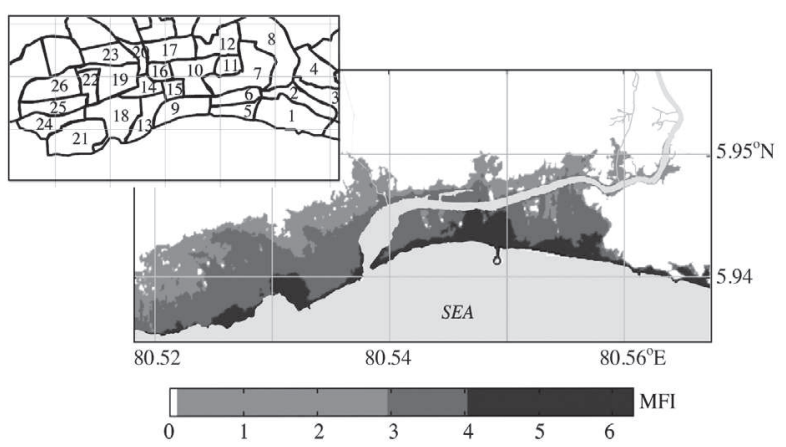

Figure 6: Spatial distribution of MFI for the city of Matara. The inset shows the GN divisions falling within the computational domain.

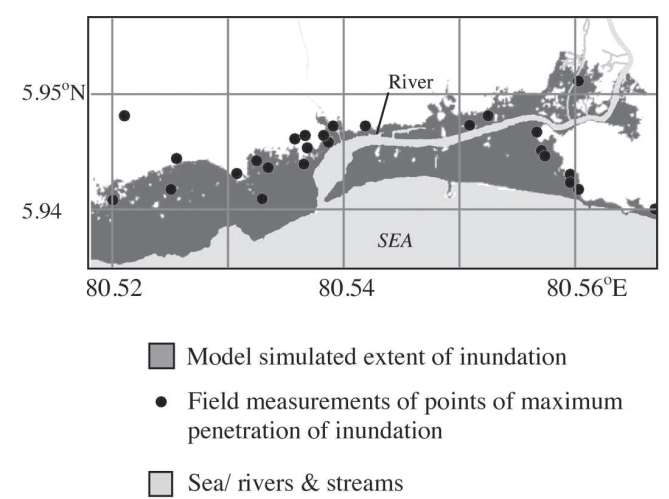

Figure 5: Comparison of model simulated extent of inundation with field measurements of points of maximum penetration of inundation in the city of Matara

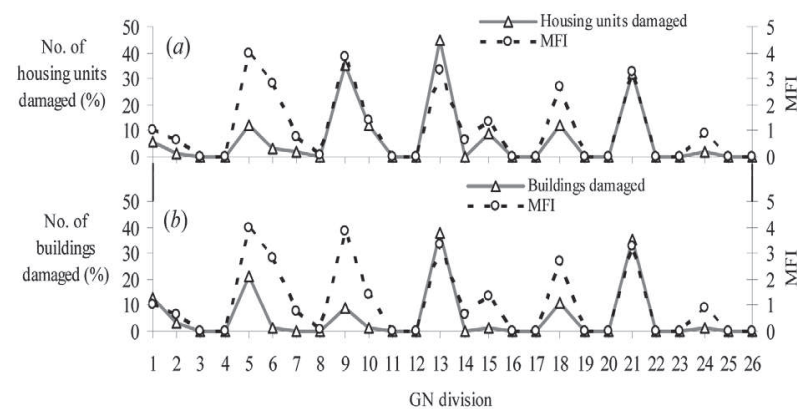

Figure 7: Comparison of the percentage of (a) housing units, and (b) other buildings, damaged in each GN division of the modelled area of the city of Matara with corresponding mean values of MFI. 
The amplitude of the 2004 tsunami during its propagation was in the order of magnitude of $1 \mathrm{~m}$, whilst the wavelength of the leading wave was in the order of magnitude of $100 \mathrm{~km}$. Thus, linear shallow water equations are adequate to solve tsunami propagation in the first, second and third level grids.

On the other hand, in the inundation areas of the fourth level grids, the water depth becomes very small and approaches zero at the tip of the surging bore. Thus, the non-linearity, i.e., the ratio between wave amplitude and water depth, could become significant. However, owing to the shallowness of the water, the frequency dispersion effects, which are represented by the water depth to wave length ratio, can still be negligible. Considering these, non-linear shallow water equations inclusive of bottom frictional terms were adopted to describe the tsunami overland flow in fourth level grids.

As the spatial extent is comparatively larger in first and second level grids, we used the linear shallow water equations on the spherical coordinate system as given in the following:

$\frac{\partial \zeta}{\partial t}+\frac{1}{R \cos \varphi}\left[\frac{\partial P}{\partial \psi}+\frac{\partial}{\partial \varphi}(\cos \varphi Q)\right]=0$

$\frac{\partial P}{\partial t}+\frac{g h_{s}}{R \cos \varphi} \frac{\partial \zeta}{\partial \psi}-f Q=0$

$\frac{\partial Q}{\partial t}+\frac{g h_{S}}{R} \frac{\partial \zeta}{\partial \varphi}+f P=0$

where, $\square$ is free surface elevation; $(\square, \varphi)$ denote the longitude and latitude of the Earth; $R$ is the Earth's radius; $P$ and $Q$ stand for the volume fluxes $\left(P=h_{s} u\right.$ and $\left.Q=h_{s} v\right)$; and $f$ represents the Coriolis force coefficient.

However, given the comparatively smaller spatial extents of the third and fourth level grids, the governing equations were solved in Cartesian coordinate system in these regions. The non-linear shallow-water equations in Cartesian coordinate system can be expressed as:

$$
\begin{aligned}
& \frac{\partial \zeta}{\partial t}+\frac{\partial P}{\partial x}+\frac{\partial Q}{\partial y}=0 \\
& \frac{\partial P}{\partial t}+\frac{\partial}{\partial x}\left(\frac{P^{2}}{h}\right)+\frac{\partial}{\partial y}\left(\frac{P Q}{h}\right)+g h \frac{\partial \zeta}{\partial x}+\tau_{x} h=0 \\
& \frac{\partial Q}{\partial t}+\frac{\partial}{\partial x}\left(\frac{P Q}{h}\right)+\frac{\partial}{\partial y}\left(\frac{Q^{2}}{h}\right)+g h \frac{\partial \zeta}{\partial y}+\tau_{y} h=0
\end{aligned}
$$

where, $\tau_{x}$ and $\tau_{y}$ are the bottom shear stresses in $x$ - and $y$-directions, respectively; and $P$ and $Q$ stand for the volume fluxes $(P=h u$ and $Q=h v)$. Moreover, because of the smaller spatial extents of the second, third and fourth level grids, the Coriolis force effect is not considered for these regions.

The bottom shear stress terms are modelled by using the Manning's formula:

$$
\begin{aligned}
& z_{x}=\frac{\rho g n^{2}}{h^{7 / 3}} P\left(P^{2}+Q^{2}\right)^{1 / 2} \\
& z_{y}=\frac{\rho g n^{2}}{h^{7 / 3}} Q\left(P^{2}+Q^{2}\right)^{1 / 2}
\end{aligned}
$$

where, $n$ is the Manning's coefficient, which represents the roughness of the land surface. In the absence of detailed information regarding the land use and given the difficulties in characterizing the roughness of an irregular surface consisting of man-made structures, a uniform value of $n=0.02$ for onshore terrain of all four cities was used.

Analysis of numerical model results: The output data files of COMCOT numerical model include water surface elevation as well as depth- averaged velocity components in longitudinal (or $x$-) and latitudinal (or $y$-) directions at each time step for each grid nested in the computational domain. Such data files for the fourth level grids were then processed using Matlab version 6.5 software to obtain the spatial variations of the maximum water depth $(h)$, the maximum current speed $(V)$ and the MFI in the four cities considered in this study.

Furthermore, the analysis of data was extended to examine the reliability of MFI as an indicator of tsunami damage compared to the two parameters typically employed in depicting tsunami hazard, i.e., $h$ and $V$. Extensive data gathered after the 2004 tsunami relating to the number of housing units and other buildings that

\begin{tabular}{|c|c|c|c|}
\hline & Location & $\begin{array}{c}\text { Geographical coordinates } \\
\text { on WGS84 (deg.) }\end{array}$ & Source \\
\hline 1 & Galle & $80.2221 \mathrm{E}, 6.0373 \mathrm{~N}$ & Tomita et al. ${ }^{19}$ \\
\hline 2 & Matara & $80.5242 \mathrm{E}, 5.9355 \mathrm{~N}$ & Shibayama et al..$^{20}$ \\
\hline 3 & Hambantota & $81.1265 \mathrm{E}, 6.1311 \mathrm{~N}$ & ditto \\
\hline 4 & Trincomalee & $81.2378 \mathrm{E}, 8.5661 \mathrm{~N}$ & Liu et $a .^{21}$ \\
\hline
\end{tabular}
were completely damaged or partially damaged but unusable have been published by the Department of Census and Statistics for affected GN divisions along the

Table 3: Coordinates of locations referred to in Figure 4 
coastal belt ${ }^{1}$. In this survey, a place of dwelling of human beings separated from other places of dwelling and with a separate entrance is termed a 'housing unit' whilst every building or part of a building which is not used as a place of dwelling is termed 'other buildings'. Such other buildings include offices, shops, hospitals, hotels and restaurants. Accordingly, a mosaic of approximate boundaries of the GN divisions covered in the modelled area of each city was laid on raster files of the spatial variation of the three flow parameters, namely, the water depth, the flow velocity and the MFI, using Global Mapper version 8.03 GIS software. Then, separate data files containing the value of each of these parameters at every grid point in each of the GN divisions were created using tools available for this purpose in Global Mapper. These data files were then used to obtain the following statistical quantities of the above three parameters (MFI, $h$ and $V$ ) for each GN division: the mean; the average of the highest one-third; and the average of the highest onetenth.

\section{RESULTS AND DISCUSSION}

\section{Verification of model results}

At the outset, field measurements of maximum water levels and the furthest extent of overland flow due to the 2004 tsunami were compared with the corresponding results from the model in order to verify the reliability of the seismic source model as well as the hydrodynamic model of tsunami propagation and inundation employed in the present study.

In Figure 4 the computed maximum water levels at selected locations close to the shoreline in the four cities were compared with those measured by post-tsunami survey teams. The coordinates of the locations where field measurements are available are given in Table 3. It is seen in Figure 4 that the computed water levels on the whole show good agreement with the field measurements, especially considering both the uncertainties involved in

Table 4: Computed values of MFI and percentage damage to housing and buildings in Matara.

\begin{tabular}{|c|c|c|c|c|c|c|}
\hline \multirow{2}{*}{ No. } & \multirow{2}{*}{ GN division } & \multirow{2}{*}{$\begin{array}{c}\text { Percentage of } \\
\text { housing units } \\
\text { damaged }\end{array}$} & \multirow{2}{*}{$\begin{array}{c}\text { Percentage of } \\
\text { buildings } \\
\text { damaged }\end{array}$} & \multicolumn{3}{|c|}{ Computed values of MFI } \\
\hline & & & & $\mathrm{MFI}_{\text {mean }}$ & $\mathrm{MFI}_{1 / 3}$ & $\mathrm{MFI}_{1 / 10}$ \\
\hline 1 & Eliyakanda South & 6 & 13 & 1.0 & 3.0 & 4.8 \\
\hline 2 & Eliyakanda North & 1 & 3 & 0.6 & 1.8 & 3.1 \\
\hline 3 & Meddawatta & 0 & 0 & 0 & 0 & 0 \\
\hline 4 & Weradoowa & 0 & 0 & 0 & 0 & 0 \\
\hline 5 & Kotuwegoda South & 12 & 21 & 4.0 & 4.6 & 4.9 \\
\hline 6 & Kotuwegoda North & 3 & 1 & 2.8 & 3.6 & 4.1 \\
\hline 7 & Uyanwatta & 2 & 0 & 0.8 & 2.3 & 3.2 \\
\hline 8 & Weragampita & 0 & 0 & 0.1 & 0.3 & 0.9 \\
\hline 9 & Fort & 35 & 9 & 3.9 & 4.4 & 4.8 \\
\hline 10 & Kadaveediya East & 12 & 1 & 1.4 & 1.7 & 3.5 \\
\hline 11 & Uyanwatta North & 0 & 0 & 0 & 0 & 0 \\
\hline 12 & Walpola & 0 & 0 & 0 & 0 & 0 \\
\hline 13 & Thotamuna & 45 & 38 & 3.4 & 4.1 & 4.3 \\
\hline 14 & Noope & 0 & 0 & 0.7 & 1.9 & 2.5 \\
\hline 15 & Kadaveediya South & 9 & 1 & 1.4 & 3.6 & 3.9 \\
\hline 16 & Kadaveediya West & 0 & 0 & 0 & 0 & 0 \\
\hline 17 & Weliweriya East & 0 & 0 & 0 & 0 & 0 \\
\hline 18 & Pamburana & 12 & 11 & 2.7 & 4.0 & 4.6 \\
\hline 19 & Welegoda East & 0 & 0 & 0 & 0 & 0 \\
\hline 20 & Weliweriya West & 0 & 0 & 0 & 0 & 0 \\
\hline 21 & Polhena & 32 & 35 & 3.2 & 3.9 & 4.2 \\
\hline 22 & Welegoda North & 0 & 0 & 0 & 0 & 0 \\
\hline 23 & Isadeen Town & 0 & 0 & 0 & 0 & 0 \\
\hline 24 & Walgama South & 2 & 1 & 0.9 & 2.3 & 2.9 \\
\hline 25 & Walgama Meda & 0 & 0 & 0 & 0 & 0 \\
\hline 26 & Walgama & 0 & 0 & 0 & 0 & 0 \\
\hline
\end{tabular}


modelling tsunami generation and propagation as well as the accuracy of post-tsunami field measurements which have to rely on evidence such as watermarks, locations of debris left at higher elevations, damage to structures and trees, etc. Most field surveys carried out in the immediate aftermath of the tsunami could have made use of the more reliable watermarks on housing and other buildings to estimate the maximum water levels. Nevertheless, it is possible that the typical surface waviness of a fast moving turbulent flow often carrying large amounts of debris and getting channelled through narrow spaces constrained by buildings and other obstructions could still result in a higher water mark. It must also be mentioned that a similar comparison for the computed flow velocities cannot be done since such field records are not available.

The numerical results were further verified by comparing the model simulated extent of overland flow with the field measurements of the points of maximum penetration of inundation reported previously ${ }^{22}$. It was found that a Manning's bottom roughness value of $n=0.02$ (which is the typical value of $n$ for firm soil) gave good agreement of model predicted extent of inundation with the measured points of limit of inundation, as shown in Figure 5, for example, for the city of Matara. There appears

Table 5: Computed values of MFI and percentage damage to housing and buildings in Galle

\begin{tabular}{|c|c|c|c|c|c|c|}
\hline \multirow{2}{*}{ No. } & \multirow{2}{*}{ GN division } & \multirow{2}{*}{$\begin{array}{l}\text { Percentage of } \\
\text { housing units } \\
\text { damaged }\end{array}$} & \multirow{2}{*}{$\begin{array}{c}\text { Percentage of } \\
\text { buildings damaged }\end{array}$} & \multicolumn{3}{|c|}{ Computed values of MFI } \\
\hline & & & & $\mathrm{MFI}_{\text {mean }}$ & $\mathrm{MFI}_{1 / 3}$ & $\mathrm{MFI}_{1 / 10}$ \\
\hline 1 & Katugoda & 34 & 39 & 3.3 & 3.7 & 3.9 \\
\hline 2 & Dewathura & 28 & 50 & 2.1 & 3.2 & 3.6 \\
\hline 3 & Magalle & 19 & 23 & 3.1 & 3.8 & 4.1 \\
\hline 4 & Makuluwa & 1 & 0 & 0.8 & 2.3 & 2.9 \\
\hline 5 & Ettiligoda South & 0 & 0 & 0 & 0 & 0 \\
\hline 6 & Milidduwa & 0 & 0 & 0 & 0 & 0 \\
\hline 7 & Pettigalawatta & 25 & 37 & 3.3 & 3.8 & 3.9 \\
\hline 8 & Thalapitiya & 14 & 10 & 2.0 & 3.3 & 3.4 \\
\hline 9 & Kongaha & 0 & 0 & 0 & 0 & 0 \\
\hline 10 & Dangedara East & 0 & 0 & 0.1 & 0.5 & 1.2 \\
\hline 11 & Weliwatta & 8 & 6 & 1.5 & 3.2 & 3.7 \\
\hline 12 & Madapatha & 0 & 0 & 0 & 0 & 0 \\
\hline 13 & Pokunawatta & 0 & 0 & 0 & 0 & 0 \\
\hline 14 & Fort & 0 & 0 & 1.1 & 2.9 & 3.7 \\
\hline 15 & Cheena Koratuwa & 13 & 45 & 3.4 & 3.8 & 4.0 \\
\hline 16 & Minuwangoda & 4 & 0 & 2.6 & 3.2 & 3.5 \\
\hline 17 & Sangamittapura & 0 & 0 & 0.1 & 0.4 & 1.3 \\
\hline 18 & Kaluwella & 15 & 7 & 1.2 & 2.8 & 3.5 \\
\hline 19 & Kandewatta & 1 & 0 & 0.5 & 1.5 & 2.4 \\
\hline 20 & Galwadugoda & 0 & 0 & 0.3 & 0.8 & 1.9 \\
\hline 21 & Mahamodara & 24 & 13 & 2.0 & 3.6 & 4.5 \\
\hline 22 & Osanagoda & 0 & 0 & 0 & 0 & 0 \\
\hline 23 & Kumbalwella South & 0 & 0 & 0.2 & 0.5 & 1.6 \\
\hline 24 & Siyambalagahawatta & 14 & 5 & 1.8 & 4.0 & 4.7 \\
\hline 25 & Bope West & 1 & 0 & 0.3 & 1.5 & 3.3 \\
\hline
\end{tabular}

Table 6: Correlation between damage to housing units and selected flow parameters

\begin{tabular}{lccc}
\hline \multirow{3}{*}{ City } & \multicolumn{3}{c}{ Correlation Coefficient $(r)$} \\
\cline { 2 - 4 } & $\begin{array}{c}\text { MFI \& damage to } \\
\text { housing units }\end{array}$ & $\begin{array}{c}\text { Flow depth }(h) \& \\
\text { damage to housing units }\end{array}$ & $\begin{array}{c}\text { Flow speed }(V) \text { \& damage } \\
\text { to housing units }\end{array}$ \\
\hline Matara & 0.8660 & 0.6830 & 0.6453 \\
Galle & 0.8290 & 0.8165 & 0.7051 \\
\hline
\end{tabular}


to be one outlier at around $\left(80.521^{\circ} \mathrm{E}, 5.948^{\circ} \mathrm{N}\right)$ : the field records indicate that tsunami flooding has travelled up to this point along a narrow, small stream; however, it was found that the $10 \mathrm{~m}$ gridding of topographic data employed in the present simulations was too coarse to fully resolve such a narrow stream, and consequently, the inability of the model to simulate flow towards this point. Similar comparisons carried out for the cities of Galle and Hambantota too showed good agreement. However, a satisfactory comparison could be seen only for about two-thirds of the coastline of the city of Trincomalee. Since high resolution LIDAR data of the onshore terrain were not available for the city of Trincomalee, it is possible that inaccuracies in the topographic data used could be one contributing factor.

\section{Momentum flux index}

\section{City of Matara}

The spatial distribution of the MFI (see eq. 4 for definition) for the city of Matara is shown in Figure 6. The results are shown in three colour bands in grey scale: values of MFI up to 3 (i.e., representing momentum flux per unit width in the order of magnitude of $10^{3} \mathrm{~N}$ ), between 3 and 4 (i.e., $10^{4} \mathrm{~N} \sim 1$ ton) and higher than 4 . We see that the MFI for the modelled area of the city of Matara falls mostly between 3 and 4 except in certain localities adjacent to the shoreline as well as closer to the furthest limit of inundation.

It is interesting to examine if any correlation exists between the computed values of MFI and the degree of damage caused by the 2004 tsunami to the housing and other buildings in the city of Matara. As comprehensive data relating to the number of structures damaged are available at the lowest administrative level of GN divisions $^{1}$, the approximate boundaries of the GN divisions falling within the computational domain covering the city of Matara are identified in the inset of Figure 6 together with Table 4 to enable such a comparison. The proportions of housing units and buildings either completely damaged or partially damaged and unusable in each GN division are also given in Table 4 as a percentage of the total number in the respective GN division. The computed values of the mean as well as the average of the highest one-third $\left(\mathrm{MFI}_{1 / 3}\right)$ and the average of the highest one-tenth $\left(\mathrm{MFI}_{1 / 10}\right)$ of the spatial variation of MFI at all grid points in each GN division are also tabulated. In addition to the mean, the computed values of $\mathrm{MFI}_{1 / 3}$ and $\mathrm{MFI}_{1 / 10}$ are also given since the latter quantities may be more appropriate for the design of structural elements subjected to potential tsunami loading. Note that an MFI value of zero was assigned to those grid points for which computed water depths were lower than $1 \mathrm{~cm}$ and thus negligible with regard to potential damage.

The GN divisions of Kotuwegoda South (No. 5 in Table 4), Fort (9), Thotamuna (13) and Polhena (21) have mean values of $\mathrm{MFI}_{\text {mean }}$ higher than 3 and values of $\mathrm{MFI}_{1 / 10}$ higher than 4; in addition to these GN divisions, Eliyakanda South (1), Kotuwegoda North (6) and Pamburana (18) too indicate values of $\mathrm{MFI}_{1 / 10}$ higher than 4.

Figure $7(a)$ compares the percentage of housing units damaged and unusable in each GN division (vertical axis on the left of the plot) with the respective mean value of MFI (vertical axis on the right). On the whole, the computed values of MFI follow the trend shown by the percentage of housing units damaged in each GN division. However, the values of MFI in the GN divisions of Kotuwegoda South (No. 5 in Table 4) and Kotuwegoda North (6) are higher compared to the overall trend of the percentage of housing units damaged for all GN divisions.

A similar comparison of the percentage of buildings damaged and unusable in each GN division with the respective average values of MFI is shown in Figure $7(b)$. The overall trends show satisfactory agreement although the mean values of MFI for the GN divisions of Kotuwegoda North (No. 6 in Table 4), Fort (9) and Kadaveediya East (10) are comparatively higher than the general trend shown by the percentage of buildings damaged.

Table 7: Correlation between damage to buildings and selected flow parameters

\begin{tabular}{lccc}
\hline \multirow{3}{*}{ City } & \multicolumn{3}{c}{ Correlation Coefficient $(r)$} \\
\cline { 2 - 4 } & $\begin{array}{c}\text { MFI \& damage to } \\
\text { buildings }\end{array}$ & $\begin{array}{c}\text { Flow depth }(h) \& \\
\text { damage to buildings }\end{array}$ & $\begin{array}{c}\text { Flow speed }(V) \& \\
\text { damage to buildings }\end{array}$ \\
\hline Matara & 0.7562 & 0.6868 & 0.7014 \\
Galle & 0.7937 & 0.7940 & 0.6215 \\
\hline
\end{tabular}




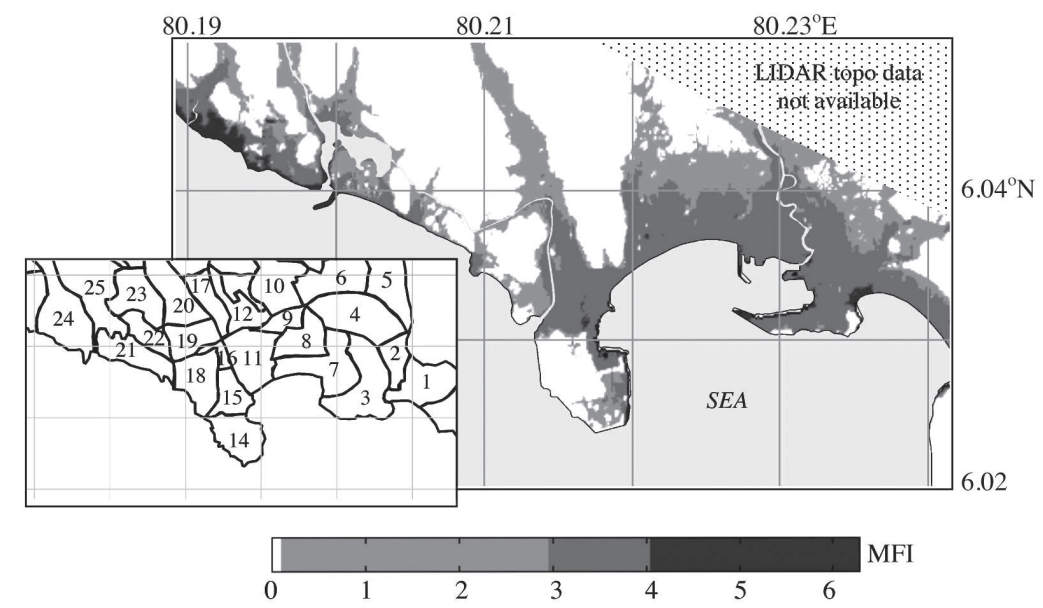

Figure 8: Spatial distribution of MFI for the city of Galle. The inset shows the GN divisions falling within the computational domain

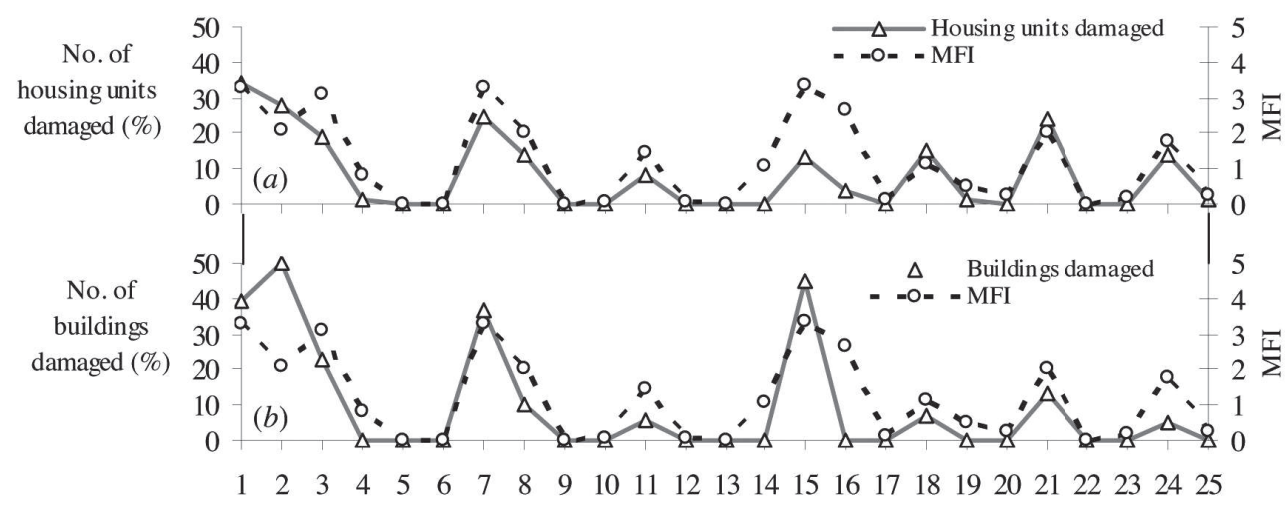

Figure 9: Comparison of the percentage of $(a)$ housing units, and ( $b$ ) other buildings, damaged in each GN division of the modelled area of the city of Galle with corresponding mean values of MFI

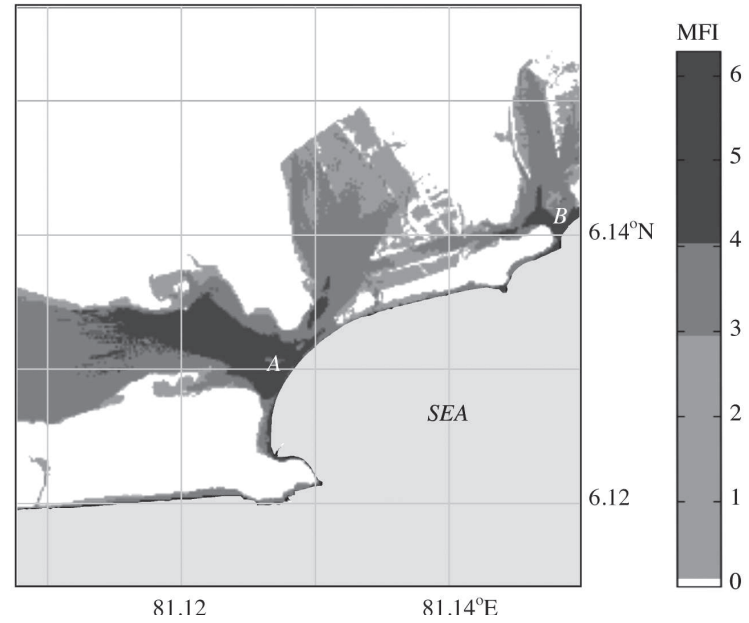

Figure 10: Spatial distribution of MFI for the city of Hambantota

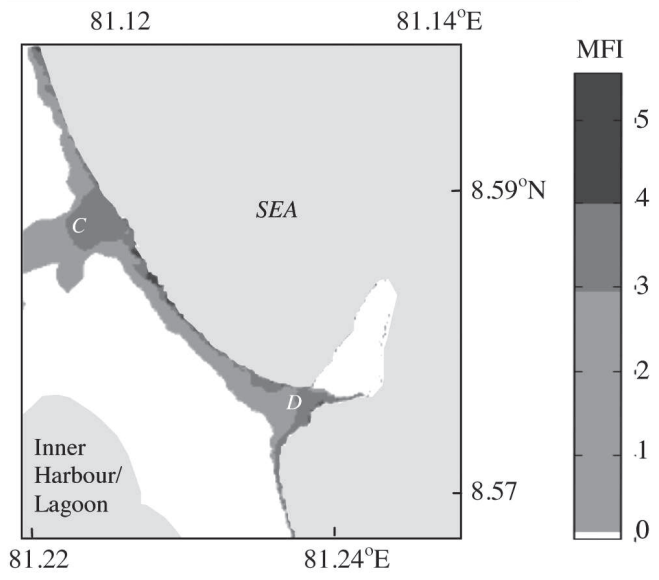

Figure 11: Spatial distribution of MFI for the city of Trincomalee 


\section{City of Galle}

Figure 8 shows the spatial distribution of MFI for the city of Galle. As for Matara, the approximate boundaries of the GN divisions falling within the modelled area of the city of Galle are identified in the inset of Figure 8 together with Table 5.

The GN divisions of Katugoda (No. 1 in Table 5), Magalle (3), Pettigalawatta (7) and Cheena Koratuwa (15) have mean values of MFI higher than 3 and values of $\mathrm{MFI}_{1 / 10}$ higher than 3.9; in addition to these GN divisions, Mahamodara (21) and Siyambalagahawatta (24) too indicate values of $\mathrm{MFI}_{1 / 10}$ higher than 4.5.

Let us now compare in Figure $9(a)$ the percentage of housing units damaged and unusable in each GN division of the city of Galle (vertical axis on the left of the plot) with the respective mean value of MFI (vertical axis on the right). On the whole, the computed values of MFI follow the trend of the percentage of housing units damaged in each GN division in the computational domain of the city of Galle. However, the values of MFI in two adjacent GN divisions of Cheena Koratuwa (No. 15 in Table 5) and Minuwangoda (16) are higher compared to the overall trend shown by the percentage damage to housing units.

A similar comparison of the percentage of buildings damaged and unusable in each GN division with the respective mean value of MFI is shown in Figure $9(b)$. As for housing units, the computed values of MFI, on the whole, also follow the variation of percentage of buildings damaged. However, the mean value of MFI for the GN division of Minuwangoda (No. 16 in Table 5) is comparatively higher than the general trend shown by the percentage of buildings damaged.

\section{City of Hambantota}

The spatial distribution of MFI for the city of Hambantota is shown in Figure 10. The momentum of the tsunami surge through location $A$ had been very high with values of MFI exceeding $4-6$. Several eyewitness reports also confirm tsunami rushing through this area with considerably high momentum. The elevated terrain to the south of this locality and the sand dune to the north-east may have contributed to this apparent rush of tsunami overland flow through the low lying ground in the vicinity of location $A$. There is also a patch of MFI higher than 4 in the vicinity of location $B$ : apparently, the sand dune at this location had been breached and the tsunami flood flow had rushed through with greater momentum.
Only two GN divisions of large spatial extent cover the entire modelled area of the city of Hambantota. Therefore, a detailed analysis of the possible correlation between MFI and percentage of housing units and buildings damaged was not attempted.

\section{City of Trincomalee}

Figure 11 suggests that the MFI for Trincomalee is lower than 3 for most areas except in a narrow strip along the coastline and in the vicinity of locations marked $C$ and $D$. This observation is consistent with the comparatively lower maximum water levels $(2.8 \mathrm{~m}$ and $3.2 \mathrm{~m})$ measured by Liu et al. ${ }^{21}$ near the city of Trincomalee and in adjacent areas in the aftermath of the 2004 tsunami.

It must be added that the numerical simulation was confined to onshore flooding directly from the eastern seaboard of the city. The field surveys confirmed overflowing of the inner harbour and lagoon in the southwestern part of the city as a result of the tsunami surge propagating into these partially enclosed waterbodies. However, the tsunami propagation inside the harbour and across the lagoon could not be simulated owing to lack of reliable bathymetric data.

Unfortunately, sufficiently comprehensive data relating to damage to housing units and buildings for all GN divisions of the modelled area of the city of Trincomalee were not available. Therefore, an analysis of the degree of correlation between the spatial variations of MFI and percentage of housing units and buildings damaged in Trincomalee was not attempted.

\section{Statistical analysis}

The results from the numerical simulations were also processed in the same way as for the MFI to obtain the mean values of flow depth and flow velocities for the GN divisions listed in Table 4 and Table 5, respectively, for the cities of Matara and Galle. The correlation between the spatial variations of the percentage of housing units damaged and each of the three flow parameters, namely, MFI, flow depth and flow velocity is given in Table 6. A similar comparison is made between the percentage of buildings damaged and each of the three flow parameters in Table 7.

Table 6 shows that the correlation coefficient $(r)$ between the MFI and the percentage of housing units damaged in Matara is significantly more than those between the flow depth and the damage as well as the flow velocity and the damage. Similarly, Table 7 indicates that the percentage of buildings damaged in Matara too 
shows a better correlation with the MFI than with the flow depth or the flow velocity. For Galle, both the MFI and the flow depth correlate almost equally well with the percentage of housing units damaged (Table 6) as well as with the percentage of buildings damaged (Table 7). However, the correlations between the flow speed and the percentages of damaged housing units as well as buildings are comparatively poor.

It must be added that the underlying presumption in the above statistical analysis is that the relation between MFI and the percentage of structures damaged is linear although these two variables need not necessarily relate linearly. Nevertheless, the satisfactory correlation shown between MFI and the percentage of housing units and buildings damaged is probably encouraging considering the fact that there are variables other than the tsunami loading that could also influence the degree of damage suffered by a structure, for example, the type of building material used (i.e., masonry or reinforced concrete), the orientation and the shape of the building, presence of cross-walls and bracings, number of storeys and the level of shielding and resistance provided by neighbouring buildings, trees and vegetation ${ }^{23}$.

\section{Model limitations}

It must be mentioned that there are several limitations involved in modelling tsunami overland flow. One is that, since the initial condition for the modelling is determined by the displacement of the ocean bottom along the fault line, the largest source of errors is the seismic source model. Another significant limitation is that the resolution of the modelling is no greater or more accurate than the bathymetric and topographic data used. Although high resolution topographic data were available for three of the four cities considered in the present study, the resolution of the bathymetric data used is much less.

The results from the present study provide an indication for local planners and designers to identify areas that are likely to be more vulnerable in terms of potential damage to property in the event of a major tsunamigenic earthquake in the Andaman-Sunda fault line and for public education and awareness activities. Because of the uncertainties inherent in this type of modelling, these results are, however, not intended for land-use regulation.

\section{CONCLUSION}

The onshore flooding caused by the 2004 Indian Ocean tsunami in four cities on the southern and eastern coasts of Sri Lanka have been numerically modelled using non-linear shallow water equations in order to examine the effectiveness of momentum flux as an indicator of the potential tsunami loading on structures. The model results have been processed to obtain the spatial distributions of the maximum values of the momentum flux as well as the depth of flooding and the flow speeds. A comparison of the computed values with the field data of the above three flow parameters show how they relate to the spatial distribution of the number of housing and other buildings damaged due to the 2004 tsunami and suggests that the spatial distribution of the percentage of housing and buildings damaged correlates better with the momentum flux than with the flow depth or the flow velocity. Extension of the present work to other parts of the affected coastal belt is recommended in order to conclusively establish the effectiveness of momentum flux in describing the potential tsunami loading.

\section{Acknowledgement}

A part of the work described in this paper was carried out with financial support from the NSF Grant No. RG/2005/ DMM/02 and USAID/IOTWS Grant No.04-05-IOTWS06. The author wishes to thank Prof. Philip Liu of Cornell University, USA for making the latest version of COMCOT FORTRAN code available in order to carry out the model simulations.

\section{References}

1. Department of Census and Statistics (2005). Atlas on the Buildings Affected by the tsunami - 2004, and Tsunami Census 2004/2005 - Final Report, Department of Census and Statistics, Colombo 07.

2. Ministry of Finance and Planning of the Government of Sri Lanka (2005). Rebuilding the tsunami Affected AreaImplementation Plan. Ministry of Finanace and Planning, The Secretariat Building, Colombo 01.

3. Hwang D. (2005). Mitigating the Risk from Coastal Hazards: Strategies \& Concepts for Recovery from the December 26, 2004 tsunami. http://www.soest.hawaii.edu/ seagrant/communication/pdf/TsunamiRecoveryReport. pdf. Accessd on 15 September 2008.

4. Walsh T.J., Titov V.V., Venturato A.J., Mofjeld H.O., \& Gonzalez F.I. (2003). Tsunami Hazard map of the Elliott Bay Area, Seattle, Washington: Modeled tsunami Inundation from a Seattle Fault Earthquake, Washington Division of Geology and Earth Resources Report No. 200314, Washington Division of Geology \& Earth Resources, Olympia, Washington.

5. Takahashi S. (2007). Tsunami disasters and their mitigation

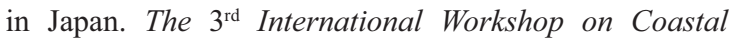
Disaster Prevention, Colombo, Feb 12-13, 2007.

6. Uslu B., Borrero J.C., Barberopoulou A.E. \& Synolakis C.E. (2007). Tsunami hazard assessment and inundation 
maps for Crescent City. Proceeding of the American Geophysical Union Fall Meeting, San Farancisco, USA, 14-18 December 2007.

7. Suleimani E.N., Combellick R.A., Marriott D., Hansen R.A., Venturato A.J. \& Newman J.C. (2005). Tsunami Hazard Maps of the Homer and Seldovia Areas, Alaska. Division of Geological \& Geophysical Surveys, Alaska, and Department of Natural Resources, Anchorage, Alaska.

8. Kanoglu U. \& Synolakis C.E. (2006). Initial value problem solution of nonlinear shallow water wave equations. Physical Review Letters 97:(14) 148501-148504.

9. Ammon C.J., Ji C., Thio H., Robinson D., Ni. S., Hjorleifsdottir V., Kanamori H., Lay T., Das S., Helmberger D., Ichinose G., Polet J. \& Wald D. (2005). Rupture process of the 2004 Sumatra-Andaman earthquake. Science 308(5725): 1133-1139.

10. Grilli S.T., Ioualalen M., Asavanant J., Shi F., Kirby J.T. \& Watts P. (2007). Source constraints and model simulation of the December 26, 2004 Indian Ocean tsunami. Journal of Waterway, Port, Coastal \& Ocean Engineering 133(6): 414 - 428.

11. Ioualalen M., Asavanant J., Kaewbanjak N., Grilli S.T., Kirby J.T. \& Watts P. (2007). Modeling the 26 December 2004 Indian Ocean tsunami: case study of impact in Thailand. Journal of Geophysical Research 112(C7).

12. Okada S. (1985). Surface displacement due to shear and tensile faults in a half-space. Bulletin of Seismological Society of America 75(4): 1135 - 1154.

13. ETOPO2 - 2 minute Worldwide Bathymetry/Topography. National Geophysical Data Center (NGDC), USA. http:// www.gfdl.noaa.gov/products/vis/data/datasets/etopo2 topo graphy.html. Accessed on 01 June 2007.

14. Liu P.L.F., Cho Y.S., Briggs M.J., Synolakis C.E. \& Kanoglu U. (1995). Run-up of solitary waves on a circular island. Journal of Fluid Mechanics 302: 259 - 285.
15. Liu P.L.F., Cho Y.-S., Yoon S.-B. \& Seo S.-N. (1994). Numerical simulations of the 1960 Chilean tsunami propagation and inundation at Hilo, Hawaii. In: Recent Development in Tsunami Research (Ed. M.I. El-Sabh), pp. 99-115. Kluwer Academic Publishers, Dordecht, The Netherlands.

16. Wang X. \& Liu Philip L. -F. (2006). An analysis of 2004 Sumatra earthquake fault plane mechanisms and Indian Ocean tsunami. Journal of Hydraulic Research 44(2): $147-154$

17. Wang X. \& Liu P.L.F. (2007). Numerical simulations of the 2004 indian ocean tsunamis coastal effects. Journal of Earthquake \& Tsunami 1(3): 273-297.

18. Cho Y.S. (1995). Numerical simulations of tsunami propagation and runup. PhD Thesis. Cornell University, New York.

19. Tomita T., Imamura F., Arikawa T., Yasuda T. \& Kawata Y. (2007). Damage caused by the 2004 Indian Ocean tsunami on the southwestern coast of Sri Lanka. Coastal Engineering Journal 48(2): 99-116.

20. Shibayama T., Okayasu A., Wijayaratna N., Sasaki J., Suzuki T. \& Jayaratna R. (2005). The December 26, 2004 Sumatra Earthquake Tsunami: Field Survey around Southern Part of Sri Lanka. http://www.cvg.ynu.ac.jp/ G2/srilanka_survey_ynu_e.html. Accessed on 01 March 2008.

21. Liu P. L. F., Lynett P., Fernando H., Jaffe B.E., Fritz H., Higman B., Morton R., Goff J. \& Synolakis C. (2005). Observations by the international tsunami survey team in Sri Lanka. Science. 308(5728): 1595.

22. Wijetunge J.J. (2006). Tsunami on 26 December 2004: spatial distribution of tsunami height and the extent of inundation in Sri Lanka. Journal of Science of Tsunami Hazards 24(3): 225 - 239.

23. Dias P., Dissanayake R. \& Chandrathilake R. (2006). Lessons learned from tsunami damage in Sri Lanka. Proceedings on ICE - Civil Engineering 159(2): 74-81. 